\title{
RESPEK VIR DIE LEWE EN DIE DOODSTRAF VOLGENS DIE PERSPEKTIEF VAN GENESIS 9:5-6
}

\author{
P. Verster ${ }^{1}$
}

\begin{abstract}
There are different views on the application of Genesis 9:5-6 in the debate on the value of life and the death penalty. In postmodern society it is considered inhumane to execute persons who committed murder. In this article different views are discussed and it is suggested that, according to Genesis 9:5, respect for life is absolute and that, although the death penalty is not explicitly mentioned, it provides an argument for upholding respect for life.
\end{abstract}

\section{INLEIDING}

Die respek vir lewe is 'n saak wat indringende etiese besinning verg. Dit is inderdaad 'n belangrike saak in 'n gemeenskap waar moord hoogty vier en waar die gemeenskap diep onder geweldsmisdaad gebuk gaan. Sommige is van mening dat die doodstraf 'n opdrag van God aan die owerheid is, juis om die respek vir lewe te verseker, en dat dit wel deur verskillende tekste (o.a. Gen. 9:5-6) bevestig word. In die post-moderne samelewing is dit egter so dat die doodstraf nie as toepaslike straf, selfs vir moord, beskou word nie. Selfs die owerheid word volgens dié beskouing nie met die doodstraf bemagtig nie en dit beteken ook dat die doodstraf nie toegepas mag word nie. Die toenemende spiraal van geweld, waar die lewe van die slagoffer minder werd geag word as die lewe van die misdadiger, vereis verdere besinning. 'n Ontleding van Genesis 9:5-6 kan moontlik lig op die saak werp. Dit is 'n teksgedeelte wat eksplisiet daarna verwys dat die lewe van die persoon wat 'n ander se lewe neem, ook geneem sal word. Verder is dit 'n gedeelte wat juis om dié rede onder etici besondere aandag geniet het.

1 Prof. P. Verster, Departement Sendingwetenskap, Fakulteit Teologie, Universiteit van die Vrystaat, Posbus 339, Bloemfontein 9300. E-pos: versterp.hum@mail. uovs.ac.za 


\section{GENESIS-NAVORSING}

Die vierbronne-hipotese aanvaar nie dat Genesis oorspronklik as eenheid onstaan het nie, maar dat dit redaksioneel uit verskeie bronne saamgestel is, naamlik die Jahwis $(\mathrm{J})$, Elohis (E), priesterlike bron (P) en moontlik 'n gesamentlike skrywer; die Deuteronomistiese skrywer (D), met 'n oerbron soms daarby (G). Van Zyl (1975:91) dui aan dat die streng verdeling reeds deur Noth afgewys is en die klem op J en mondelinge oorlewerings gelê is. Childs (1979:114) toon aan dat die gebrek aan nuwe konsensus navorsers steeds noop om ten minste 'n veelheid van bronne te erken. Wat egter wel duidelik word, is dat die literêre eenheid van veel groter belang geag word, met besondere aandag aan die kanoniese vorm van die boek Genesis (Childs 1979:145). Verder dui Childs (1979:155) aan dat Genesis 1-11 juis die voorrang van die skepping as werk van God bevestig en dus die Goddelike verhouding met sy skepping daarstel, en dat Israel se verlossingstaak die versoening van die nasies binne die eskatologiese raam van die boek insluit. Birch et al. (1999:65) vat die implikasies van Genesis 1-11 mooi saam. Hulle dui aan dat God inderdaad die wêreld goed geskape het en dat sy skeppingswerk juis as teken van die goeie duidelik was, maar dat sonde 'n vernietigende invloed daarop het:

The subsequent entrance of sin, while not finally effacing the Godhuman relationship or the key role human beings play in the divine economy, has occasioned deep and pervasive ill effects upon all relationships, human and nonhuman. These effects issue in a universal disaster for the earth, and dramatically evidence the need for a reclamation of the creation.

Birch et al. (1999:65) toon dan aan dat God nie besluit om almal en alles uit te wis nie, maar wel om deur' $n$ proses van betrokkenheid by 'n verwonde wêreld te kies vir die voortgaande behoud van sy skepping:

The world continues to live and breathe, and to establish families and nations, because God makes a gracious, unconditional commitment to stay with the world, come what may in the wake of human sinfullness.

Westermann (1986:48) plaas Genesis 6-9 binne die raamwerk van oortreding en oordeel, maar dui aan dat die verhaal van die begenadiging van die enkeling ná die vloed eerder na vore kom. Die vroeëre debat oor die verhouding tot die Gilgamesh-epos is later oorskadu 
deur die erkenning dat talle verhale wel 'n groot vloed as agtergrond het (Westermann1986:48). Dit neem egter nie die unieke waarde van die weergawe van die Bybel weg nie. Van Zyl (1975:112) merk op dat Genesis 9:1-17 weens die onderskeiding van diere in rein en onrein reeds die priesterlike agtergrond veronderstel. Hy toon aan dat die verwysing na die duif as 'n rein voël wat ook as die boodskapper van goeie tyding optree, ${ }^{2}$ hierdie saak beklemtoon. Ook die verwysing na die offer waarop Noag se redding uitloop, bevestig die vermoede dat hier met priesterlike vormgewing in die tempel te make is. Van Zyl (1975:112) is ook van mening dat die verwysings na bloed met die priesterlike vormgewing saamhang. Van Selms (1979:123) stel dit duidelik dat daar hier nie sprake van bloedwraak is soos by Kain en Lameg nie, want slegs die moordenaar, en nie sy familielede nie, moet gedood word (vgl. Deut. 24:16 en 2 Kon. 14:6.).

Daar blyk tog literêre eenheid te midde van die verskillende bronne te wees. In dié gedeelte is dit duidelik dat daar 'n verband met die geheel bestaan, al word die priesterlike uitgangspunte erken. Gunkel (1977:149) toon duidelik die verband met $\mathrm{P}$ aan. Hy wys daarop dat die verbod op die vergieting van bloed juis die priesterlike agtergrond veronderstel en daarom in $\mathrm{P}$ begrond is. Hierdie verbod is naas $\mathrm{P}$ se beklemtoning van die Sabbat-gebod die sterkste gebod in die wet. Gunkel meen dat die doodstraf in Levitikus 17 daaruit voortvloei.

Scheffler (2000:161-163) is op sy beurt oortuig dat die Priesterdokument as sentrale uitgangspunt die gevaar van die verlies van identiteit in die ballingskap het. Ou verhale, wette en kultiese voorskrifte is dus in herinnering geroep om die geloofsgemeenskap weer identiteit as volk van God te gee. Weens die blootstelling aan die Babiloniese omgewing en godsdiens moes hulle ook daarop reageer. Die reformasie en herstel van die gemeenskap het vooropgestaan. Die Noaggeskiedenis, met die voorskrifte wat aan hom gegee word, speel 'n belangrike rol. God se wette is dus van die grootste belang.

Die sondvloedverhaal word ook as teenhanger van die skeppingsverhaal beskou. Waar God aanvanklik "gesien" het dat alles goed is,

2 Dit is volgens Van Zyl (1975:112) in teenstelling met die wilde en onrein kraai wat nog nie kon aandui dat daar droë grond is nie. 
sien Hy hier dat die mense se boosheid "baie" geword het (Van Zyl 1975:112). 'n Nuwe begin word gemaak en die verhaal dui juis aan dat hierdie nuwe begin ook die respek vir lewe moet veronderstel. Dit is dus duidelik dat die kosbaarheid van die lewe in die Priesterdokument sterk beklemtoon word en as grondslag vir die interpretasie van dié gedeelte moet dien.

\section{EKSEGETIESE ONTLEDING VAN GENESIS 9:5-6}

\subsection{Grammatiese vormgewing}

Gunkel het reeds aangetoon dat die metriese 3:3-patroon gevolg word (Westermann 1984: 467). 6a vorm ook'n chiastiese struktuur wat soms met Matteus 26:52 in verband gebring word. Daar bestaan egter verskil van mening of dit 'n spreuk, profetiese uitspraak of juridiese formule is (1984:467). Westermann (1984:467) self verwys na Liedke wat tog in die lig van Eksodus 19:12b van mening is dat die gedeelte juridies van aard is, in die genre van die apodiktiese wet met die dood as straf. Liedke (Westermann 1984:467) toon egter ook die verskille met die apodiktiese wet aan. Scheffler (2000:163) toon aan dat $\mathrm{P}$ die tradisie verbind aan spesifieke voorskrifte om daardeur aan te dui dat die nakoming van die voorskrifte noodsaaklik is vir die voortbestaan van die gemeenskap. Dit is dus duidelik dat die voorskrifte wat hier aangebied word, ook van groot belang vir die geloofsgemeenskap is. Westermann (1986:99-100) dui aan dat die regstaal nie beslissend is nie, maar wel die oordeel wat in die antieke tyd voltrek is op grond van die gode se reg.

Die Hebreeuse teks, in stiges opgedeel, lees soos volg:

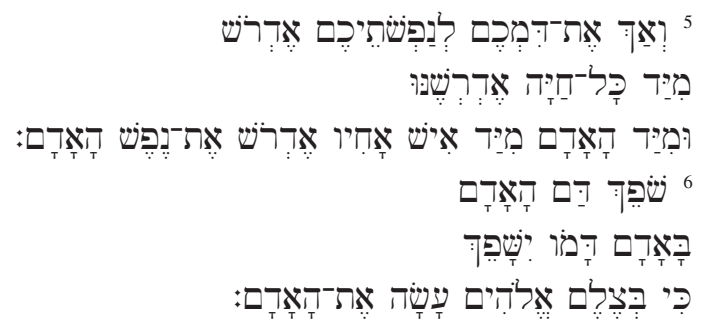


Maar wat julle eie bloed betref, dit sal Ek eis: van al die diere sal Ek dit eis. Ook van die mens, van die een teenoor die ander, sal Ek die siel van die mens eis. Hy wat die bloed van 'n mens vergiet, sy bloed sal deur die mens vergiet word; want God het die mens na sy beeld gemaak (1933 Afr. Vert.).

Wanneer julle eie bloed vergiet word, sal Ek daaroor rekenskap eis, want dit is julle lewe: van 'n dier sal ek rekenskap eis oor die lewe van 'n mens, en van 'n mens sal ek rekenskap eis oor die lewe van sy medemens.

Wie die bloed van 'n mens vergiet,

Deur 'n mens sal sy bloed vergiet word.

God het die mens gemaak

as sy verteenwoordiger (NAV).

Uit die analise is die klem op "vergiet" $(\text { ש })^{3}$ duidelik, asook op "rekenskap eis" (דרש), ${ }^{4}$ wat opbou tot die erkenning dat God die mens gemaak het as sy verteenwoordiger of na sy beeld (צלם).

Die kosbaarheid van die lewe word in die gedeelte beklemtoon deur die opbou tot die bevestiging dat die mens na God se beeld geskape is. Brueggemann (1982:83) stel dit soos volg:

An old statement on blood has now been transformed into an affirmation about human life and human worth. This decree urges human enhancement and the valuing of human persons. In this post-flood decree of creation, the sanctity of human life is established against every ideology and every force which could cheapen or diminish life.

\subsection{Die struktuur van die narratief}

Indien aanvaar word dat die narratief binne die raam van die priesterdiens verstaan moet word, is dit duidelik dat die aktante in die gedeelte God, Noag, die mens en die dier is. God tree nou op en seën Noag en sy seuns (vgl. die seëninge in Numeri.). God is duidelik die Hoofaktant wat sy seën gebied en ook die mens vreugde in die lewe gee. Die mens as aktant ontvang van God sy seën; die vrugbaarheids-

3 Koehler \& Baumgartner (2001b:1629) vertaal dit as "pour out " of "spill" of "shed blood".

4 Koehler \& Baumgartner (2001a:233) vertaal dit (saam met Akk) as "to require (someone's blood, life)."

5 Koehler \& Baumgartner (2001b:1629) vertaal dit met "God's image, i.e. he is God's viceroy, representative or witness among the creatures." 
opdrag word herhaal. Die mens se verantwoordelikheid word ook beklemtoon. Die dier is tot beskikking van die mens, maar mag nie geëet word met sy bloed nie (vgl. Numeri en Levitikus). Die ondergeskikte aktante moet almal die kosbaarheid van die lewe erken en dus die respek vir lewe handhaaf. Die mens, as verteenwoordiger van God, se bloed mag nie vergiet word nie, maar indien dit wel gebeur, kom daar 'n relasie in werking waarin die vergieting van die dader se bloed vereis word. Daarteenoor die opdrag "Wees vrugbaar. Kies die lewe!" Die stelling "God het die mens gemaak as sy verteenwoordiger" (:6) is die wentelpunt van die gedeelte en bevestig dat die mens as aktant voor die aangesig van God leef. Brueggemann (1997:452) dui aan dat dié aspek onveranderd bly, ook ná die sondeval.

Westermann (1986:99-100) wys op die samehang in die gedeelte en dui aan dat God wat die Heerser oor die lewe van die diere is, ook Heerser oor die lewe van die mense is:

Deswegen gilt das Gebot “Du sollst nicht töten!" unbedingt und unbegrenzt für die Menschheit. Der Satz is beherrscht von dem dreifachen "Ich will es einfordern!". Der Mord eines Menschen an einem Menschen wird hier ausdrücklich als Brudermord bezeichnet.

Hy wys daarop dat die mens na God se beeld gemaak is. Moord is 'n direkte ingreep in God se heersersreg.

Die narratief bou dus op tot die beginsel dat die mens God se verteenwoordiger is en dat lewe kosbaar is.

\subsection{Kommunikatiewe vormgewing}

Grice (1989:26) se gespreksvoorwaardes is soos volg: Kwaliteit (waarheid), kwantiteit (ekonomie), wyse (duidelikheid) en relevansie (wees relevant). Hoflikheid as oorkoepelende voorwaarde word bygevoeg. Dit beteken dat daar in die proses van kommunikasie so eg as moontlik, met so min inligting as nodig, so op die punt af as moontlik en so juis of relevant as moontlik met soveel hoflike oordrag as moontlik gekommunikeer moet word. Waar hierdie voorwaardes in kommunikasie in gesprekke oortree word, ontstaan implikasies. In tekste kan ook aangedui word hoe implikasies juis met die oordra van inligting ontstaan. Die skrywer wil hier met die oortreding van die gespreksvoorwaardes sekere sake duidelik makk. Hy oortree die voorwaarde 
van kwaliteit (waarheid) deur nie slegs 'n stelling te maak oor die waarde van die lewe nie, maar ook deur die aspek van die dood by te bring. Hy bevestig sy saak deur op meer as een wyse na die waarde van lewe te verwys. Sodoende versterk hy die saak dat God oor lewe waak en oortree in die proses die gespreksvoorwaarde van kwantiteit. So onstaan die implikasie dat lewe ononderhandelbaar is. Hy rig hom nie op een saak nie en haal byvoorbeeld die diere se rol, wat nie relevant vir die saak van menslike lewe is nie, by om so die gespreksvoorwaarde van wyse en relevansie te oortree. Die saak met betrekking tot respek vir lewe, word sodoende egter veel sterker uitgebou. Die oordeel van God oor die een wat lewe neem, staan vas. Lewe is kosbaar en moet gerespekteer word. Die een wat lewe neem, is skuldig. Volgens Brueggemann (1997:456) bly die mens onder die gesag van God die Skepper, al sou hy of sy die gesag van God ontken. Die mens ontvang lewensruimte van God en God gee dit met vreugde aan die mens, maar eis ook die reg vir Homself op om die grense van die mens te bepaal.

\subsection{Ou-Testamentiese teologiese vormgewing}

Die verband met die gebod van God in die dekaloog is ook van belang. Die verwysing na die sesde gebod "Jy mag nie doodslaan nie," is ook ter sprake. In die Ou-Testamentiese teologie is dit dus duidelik dat die waarde van lewe ten alle koste beskerm moet word en dat daar daarom ook maatreëls moet wees om lewe te beskerm. Die etiese implikasie van die gebod is duidelik. Die lewe is deur God gegee en is daarom kosbaar. Lewe móét beskerm word. Die dekaloog bevestig dat God die Een is wat oor die lewe waak. Die implikasie dat God ook self die Een is wat die lewe beskerm, is ook duidelik. Die lewe is geen toevallige saak nie. Lewe kom van God — dit is God se guns aan die mense. Indien die lewe geneem word, kom die oordeel van God ter sprake. Verder is dit duidelik dat God alleen die reg het om oor lewe en dood te beskik. Childs (1985:79) wys daarop dat die gebod juis die onregmatige doodmaak verbied om die waarde van lewe binne die verbond te bevestig. Selfbelang en magsmisbruik word duidelik veroordeel. God self het die reg om te beskik oor lewe en dood (1 Sam. 2:6). Brueggemann (1997:201) dui ook aan dat al die lewensmoontlikhede soos wat dit in die skepping voorkom, van God se wet 
afhanklik is. Dit is juis die waarborg teen nihilisme. Lewe is juis kosbaar en essensieel omdat God dit moontlik maak.

\section{DIE VRAAGSTELLING}

Die vraag wat gestel moet word is of dié gedeelte enige moontlikheid ooplaat om die doodstraf ter beskerming van lewe, weens die kosbaarheid van die lewe, te begrond. Van Selms (1979:123) wys daarop dat 'n meganiese Skrifgebruik hierdie teks as begronding van die doodstraf gebruik en die afskaffing daarvan as oortreding van God se gebod beskou. Hy verwys egter na Moses en Dawid en die moordenaar aan die kruis wat genade ontvang het. Vosloo (1999:32) sluit by hierdie standpunt aan deur uit te wys dat Genesis 9:5-6 nie gebruik kan word om die doodstraf te bepleit nie. Daar is volgens die skrywer geen opdrag dat die mens die doodstraf moet toepas nie. Hy plaas hierdie gedeelte binne die verband van God wat self rekenskap eis. Kidner (1967:101) meen ook dat alle lewe in God se hande is, veral dié van mense, maar dat die doodstraf op veel sterker en wyer getuienis begrond moet word.

Daarteenoor stel Richardson (1953:109) dit egter onomwonde:

By man shall his blood be shed. This verse gives to men the right to put murderers (but no one else) to death. In earlier times it was the duty of the next-of-kin (go-el, see notes on Gen. 4:10, 15); in later times it is the duty of the state. This verse is very significant, because there is implied in it the setting up of civil government in human society, with power even of life and death.

Wenham (1987:1940) toon op sy beurt aan dat die mens alleenlik die doodstraf mag toepas as hy of sy die unieke reg van God op lewe erken. Ook Sailhamer (1990:94) lê groot klem op die feit dat die mens God se beeld vertoon. Gispen (1974:296) toon veral aan dat die aspek van die mens as beeld van God besonder sterk beklemtoon word (Gen. 1:26; 5:1 en 3.). As die mens aangerand word, word die Maker ook aangerand en dit kan nie ongestraf bly nie. Gispen is egter van mening dat die wyse van straf nie uitgespel word nie (Eks. 21:12; Lev. 24:17; Num. 35:9-34). Hy wil dus nie uit die gedeelte 'n algemene reël vir die toepassing van die doodstraf aflei nie en meen dat ander gedeeltes daarop dui dat God self wil dat elke geval afson- 
derlik beoordeel word (Gen. 4:11-15; Num. 35:9-34; Eks. 21:13; Deut. 19:1-13; Eks. 22:2; Deut. 19:15).

Die eksegetiese vraag is dus: Is dié gedeelte 'n opdrag of is dit 'n stelling? Westermann (1984:468) kies daarvoor dat dit 'n stelling is. Moord word afgewys, maar alhoewel God sy gesag dinamies toeken aan die mens beteken dit nie dat die mens nou die doodstraf mag toepas nie. Aalders (1981:185) meen dit is nie duidelik dat alle moordenaars, selfs die doelbewuste moordenaars, tereggestel moet word nie. In die lig van die voorafgaande ontleding is dit egter duidelik dat dit nie net ' $n$ stand van sake aandui nie. Dit dui dus nie net op die feit dat die mens self oordeel oor hulle wat lewe neem nie. Dit dui ook op die feit dat die mens as verteenwoordiger van God optree. Krašovec (1999:43) bevestig dié gedagte deur God se reg te beklemtoon:

God himself will demand the reckoning for the shedding of human blood, and v. $6 \mathrm{~b}$ provides the reason: God applies the law of retaliation because he has created humankind in his own image. He created it for a special purpose. In the light of this, any shedding of human blood amounts to a direct encroachment upon God's plan and sovereignty.

\section{IMPLIKASIES}

Dit moet duidelik wees dat God die eis tot die respek van lewe handhaaf en so hoog ag dat dit teen die moordenaar beskerm moet word. Elke persoon se lewe is kosbaar voor God (Brueggemann 1982:83). Dit sou immers vreemd voorkom indien priesterlike erkenning van die respek vir lewe as blote stand van sake voorgestel word. Die standpunt wat aandui dat daar wel deur die gesag van God opgetree word wanneer die mens die moord van die mens met die dood straf word, word dus wel hier bevestig. Dit word hier begrens deur die gesag van God, en geskied binne die gemeenskap van God waar die priesterlike gesag geld. Dit is dus eksegeties wel moontlik om ten minste die moontlikheid van die doodstraf hier oop te laat. Sekere hermeneutiese vrae en ook die beginsel om Skrif met Skrif te vergelyk sal in die verdere ondersoek na vore moet kom. Die Christologiese lees van die teks sal nie die eis tot die reg van God wegneem nie, maar juis ook die kosbaarheid van die lewe beklemtoon. Dit is inderdaad ook die skrywer se opinie dat die doodstraf slegs in uiters uitsonderlike gevalle toegepas mag word. Alhoewel daar nie afgelei kan word dat die doodstraf 
wel onder alle omstandighede van moord toegepas móét word nie, is dit tog moontlik om uit die gedeelte af te lei dat, weens die Skrif se groot respek vir lewe, die doodstraf in uitsonderlike gevalle van moord wel in beginsel begrondbaar is, omdat die kosbare waarde van die lewe juis so beskerm word.

\section{BIBLIOGRAFIE}

\section{AALDERS G C}

1981. Genesis Vol. I. (tr. W. Heynen). Grand Rapids, Mich.: Zondervan. Bible Student's Commentary.

Biblia Hebraica Stuttgartensia 1990. Stuttgart: Deutsche Bibelgesellschaft.

BIRCH B C et al.

1999. A theological introduction to the Old Testament. Nashville: Abingdon Press.

\section{BRUEGGEMANN W}

1982. Genesis. Interpretation, a Bible commentary for teaching and preaching. Atlanta: John Knox.

1997. Theology of the Old Testament: testimony, dispute, advocacy. Minneapolis: Augsburg Fortress.

Bybel

1983. Nuwe Vertaling (met herformulerings). Kaapstad: Bybelgenootskap van Suid-Afrika.

1933. (Hersien 1953). Kaapstad: Bybelgenootskap van Suid-Afrika.

\section{CHILDS B S}

1979. Introduction to the Old Testament as Scripture. London: SCM.

1985. Old Testament theology in a canonical context. London: SCM.

\section{GISPEN W H}

1974. Genesis. Kampen: Kok. Commentaar op het Oude Testament.

\section{GRICE H P}

1989. Studies in the way of words. Cambridge: Harvard University Press.

\section{GUNKEL H}

1977. Genesis. (9. Aufl.). Göttingen: Vandenhoeck \& Ruprecht. 
KIDNER D

1967. Genesis: an introduction and commentary. Leicester: Inter-Varsity Press.

\section{KoeHLer L \& BAumgartner W}

2001a. The Hebrew and Aramaic lexicon of the Old Testament. (Revised by W. Baumgartner \& J.J. Stamm.) Study Ed. Vol. 1 (Translated and Edited under supervision of M.E.J. Richardson). Leiden: Brill.

2001b. The Hebrew and Aramaic Lexicon of the Old Testament. (Revised by W. Baumgartner \& J.J. Stamm.) Study Ed. Vol. II (Translated and edited under supervision of M.E.J. Richardson). Leiden: Brill.

KRAŠOvEC JožE

1999. Reward, punishment and forgiveness: the thinking and beliefs of ancient Israel in the light of Greek and modern views. Leiden: Brill.

\section{RiCHARDSON A}

1953. Genesis 11. London. SCM.

\section{SAILHAMER J H}

1990. Genesis. The Expositor's Bible Commentary. Vol. 2 (Genesis-Numbers) (F.E. Gaebelein, ed.). Grand Rapids: Zondervan.

\section{SCHEFFLER E}

2000. The exilic literature. In: W. Boshoff, E. Scheffler \& I. Spangenberg (reds.), Ancient literature in context (Pretoria: Protea), pp. 161-164.

\section{VAN SELmS A}

1979. Genesis. Deel I. Nijkerk: Callenbach.

\section{VAN ZYL A H}

1975. Gods Woord in Mensetaal. Deel 1. Die ontstaan van die eerste vyf boeke van die Bybel. Durban: Butterworths.

\section{VosLoo W}

1999. Genesis. In: W. Vosloo \& F. van Rensburg (reds.), Die Bybellennium: een volume kommentaar. Die Bybel uitgelê vir eietydse toepassing (Vereeniging: Christelike Uitgewersmaatskappy), pp. 3-71.

\section{WENHAM G J}

1987. Genesis 1-15. Waco: Word Books. Word Biblical Commentary: Vol. I.

\section{WESTERMANN C}

1986. Am Anfang. 1. Mose (Genesis): Teil 1. Die Urgeschichte — Abrabam. NeukirchenVluyn: Neukirchener Verlag.

1984. Genesis 1-11: a commentary. Minneapolis: Augsburg Publishing House. 
Acta Theologica

2004:2

Trefwoorde

Respek vir lewe

Doodstraf

Genesis 9:5-6

Regverdiging van die doodstraf
Keywords

Respect for life

Death penalty

Genesis 9:5-6

Justification of the death penalty 